\title{
Medications adherence level and its associated factors among hypertensive patients at a major referral hospital, in Riyadh, KSA
}

\author{
Shaffi Ahamed Shaik ${ }^{1}$, Abeer Alsuwailem², Afnan Alhargan², Asma Alswailem², \\ Dania Alshiha ${ }^{2}$, Hanan AIGhalib'2 ${ }^{2}$ Raghdah Alamri², Ali Al-Hazmi ${ }^{3}$
}

${ }^{1}$ Associate Professor, Department of Family \& Community Medicine, College of Medicine, King Saud University, Riyadh, Saudi Arabia, ${ }^{2}$ Medical Students, Department of Family \& Community Medicine, College of Medicine, King Saud University, Riyadh, Saudi Arabia, ${ }^{3}$ Assistant Professor, Chairman, Department of Family \& Community Medicine, College of Medicine, King Saud University, Riyadh, Saudi Arabia

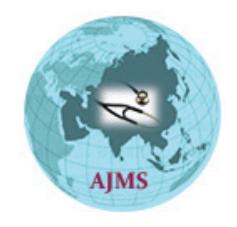

A B S T R A C T

Aims and Objectives: To quantify the level of medications adherence among hypertensive patients and to identify factors of poor adherence. Materials and Methods: A cross sectional study was conducted during October 2013 to March 2014 in King Khalid University Hospital, Riyadh, KSA. Self-administrative questionnaires were used among 310 randomly selected hypertensive patients. Morisky adherence questionnaire was used to quantify adherence level of medications. Adherence scores were categorized as poor and high adherence. Bi-variate and multivariate analysis were used to identity factors associated with poor adherence. Results: Out of 282 patients who had responded, 124(44\%) were of less than 50 years of age. Prevalence of poor adherence to medications was $55 \%$. Age, educational status, monthly income, time of diagnosis, self-perception of health status, regular checkup at clinics, \& regular blood pressure checkup were significantly associated with 'level of adherence (poor and high) to medications. The independent associated factors of poor adherence were: age ( $<50$ years): 2.30 (95\% confidence interval(CI): $1.29,4.10)$, monthly income $(<5000$ Saudi Riyals): $6.58(1.67,25.97)$, self-perception of health status (uncontrolled): $2.66(1.20,5.90)$, and regular checkup at clinics (No): 5.57(2.83,10.97). Conclusion: Level of adherence was low among hypertensive patients. Associated factors of poor adherence could be used to identity patients for counselling in improving level of adherence to medications.

Access this article online

Website:

http://nepjol.info/index.php/AJMS DOI: 10.3126/ajms.v7i4.14085 E-ISSN: 2091-0576 P-ISSN: 2467-9100

Key words: Hypertension, Adherence, Medications, Associated factors, Saudi Arabia

\section{INTRODUCTION}

Hypertension (HTN) is defined as having persistent, elevated blood pressure of $140 \mathrm{mmHg}$ or above and/or diastolic blood pressure of $90 \mathrm{mmHg}$ above. In spite of improved treatment strategies for hypertension, many studies reported that HTN contribute significantly to mortality and morbidity in adults as it is poorly controlled. ${ }^{1}$ It is a worldwide public health burden because of its chronicity and financial costs. HTN prevalence is increasing rapidly in the Kingdom of Saudi Arabia (KSA) as one fourth of Saudis have HTN. ${ }^{2}$ Another study has found that the central region of the country have the highest prevalence of HTN compared to other regions. ${ }^{3}$ Different guidelines exist for the management of HTN and JNC 7 is one of them. Following JNC 7, current control rates are (SBP $<140 \mathrm{mmHg}$ and DBP $<90 \mathrm{mmHg}$ ) or $(<130 / 80 \mathrm{mmHg}$ for patients with diabetes or chronic kidney disease). ${ }^{4}$ However, a study in Saudi retrieved that as much as $24.90 \%$ of the surveyed population aged between 
25-64 years had a systolic blood pressure $\geq 140 \mathrm{~mm}$ of $\mathrm{Hg}$ (Uncontrolled) including people taking medical treatment for raised blood pressure. ${ }^{5}$ Managing HTN can be through lifestyle modification or pharmacological agents such as diuretics, angiotensin converting enzyme (ACE) inhibitors, calcium channel blockers (CCBs), angiotensin receptor blockers (ARBs) and beta-blockers.

The world health organization defined medication adherence as "the extent to which a person's behavior corresponds with agreed recommendations from a healthcare provider". ${ }^{6}$ This definition is clearly explained and simply means that the patients follow what the physician/doctor has suggested. Prescribing medications, in the healthcare sector, is the main part of treatment as they improve the disease outcome and decrease the complications. ${ }^{7}$ According to a study done in the United States, in order for a medication to be effective, patients has to adhere to their prescribed medications. However, in chronic illnesses, patients have difficulty adhering to their medications; this explains why not all patients are adhered to their medications. Nearly $50 \%$ of them discontinued taking their medications after one year. Not adhering to medications is considered a public health issue, because it easily can lead to a poor quality of life, further complications, worsening of the condition and hospitalization which all eventually will increase the risk of death. ${ }^{8}$ In additions to the health related problems resulting from non-adherence to medications, a financial burden is also considered a major issue. Uncontrolled hypertension may lead to many serious complications such as atherosclerosis, heart attacks, strokes, aneurysms, vascular dementia, kidney disease and eye disease. ${ }^{9}$ The prevalence of stroke, myocardial infarction and heart failure can be reduced by $35-40 \%, 20-25 \%$ and $>50 \%$ respectively when using antihypertensive treatments. ${ }^{4}$ These figures are promising, but unfortunately in Saudi; a past study found only $37.0 \%$ of patients receiving pharmacological therapies were controlled for hypertension. ${ }^{10}$ Medication adherence usually refers to whether patients take their medications as prescribed as well as whether they continue to take a prescribed medication. Patients were considered to be adherent if they reported taking $\geq 80 \%$ of their doses as prescribed by their physicians. ${ }^{11}$ Non adherence to medications is a big concern to clinicians and healthcare systems. The factors contributing to poor medication adherence are countless which are related to patients, treating physicians and to health care providing facilities. ${ }^{12}$ On the other hand the healthcare practitioners cannot supervise or keep eye on patients of each day of the medication compliance process; they just can play a unique and important role on giving patients necessary knowledge towards adherence of medication through regular interactions. ${ }^{13}$
The objectives of this study are to quantify the level of medication adherence among the hypertensive patients in a major referral hospital. And also to identify the factors associated with poor adherence.

\section{MATERIALS AND METHODS}

An Observational quantitative cross sectional study was conducted between October, 2013 and March, 2014, at hypertension clinics and outpatient department in King Khalid University Hospital, Riyadh, KSA. The study subjects were the patients' diagnosed with hypertension. By considering a prevalence of adherence of $72 \%{ }^{13}$ among these patients, with a precision of $5 \%$ at 0.05 level of significance, a sample of 310 patients were the study subjects. Patients were selected using random time intervals on each day of study period. A pre-tested structured self-administrative questionnaire was used. The study variables were: age, gender, marital status, residency, level of education, number of people in the house, working status and income, time of diagnosis, what would you say about your condition, regular clinic check, regular home check and number of medication, taking medication factor, psychological factor, financial factor and Healthcare providers and medical system factors and the health problems. While the outcome variable is: prevalence of adherence to drugs among patients with hypertension. Patient's adherence to medications was measured using the 8-item Morisky medication adherence scale (MMAS), which is a self-report measure of medication taking behavior. This was well-validated instrument developed by Morisky etal. ${ }^{14}$ MMAS has good validity and reliability, has used to assess adherence of patients suffering from chronic diseases. MMAS consists of eight items that address specific medication-taking behavior and adherence. The first 7 items have dichotomous responses (Yes/No) and last question is answered on a 5-point Likert scale. One point is given for each sentence based on the answer. In the first 7 questions, one point is given for each "NO" answer except for question number 5 where on point is given for the "YES" answer. For question number 8, one point is given for "never/rarely" item and zero is given for "all the time" item. The total score ranges from 0 to 8 , with better scores representing better adherence. Study subjects who score of less than 6 are considered to have poor adherence and those who score 6 or more are considered to high adheres.

\section{Data Analysis}

Data was analyzed using Statistical Package for the Social Sciences (SPSS) version 21.0. Descriptive statistics (mean, standard deviation, frequencies and percentages) were used to describe the quantitative and categorical variables. Bi-variate and multivariate (binary logistic regression) were 
used to obtain Unadjusted and adjusted odds ratios so as to measure the association between the categorical study variables and binary outcome variable. A p-value of $<0.05$ and $95 \%$ confidence intervals were used to report the statistical significance and precision of results.

\section{Ethical consent}

The consent was obtained from the study subjects before administering the questionnaire. IRB approval was obtained to carry on with the study.

\section{RESULTS}

Out of 310 study subjects, 282(90.9\%) had responded to the study. Mean (standard deviation) age was 52(12.05) years. Female patients were $60.6 \%$ and $219(77.6 \%)$ patients were married. The distribution of educational status was illiterates $(15.6 \%)$, college graduates $(29.8 \%)$, and post graduates $(7.1 \%)$. Monthly income of these patients was less than 5000 Saudi Riyal (SR) in 22\%, 5001-10000 in $30.5 \%$ and greater than 30,000 SR was in $5.7 \%$ of patients. Out of 282 patients, 155 (55\%, 95\% condifience interval: $49 \%$ to $61 \%$.) were having poor adherence to medications.

\section{Associated factors of poor adherence (by bivariate multivariat analysis)}

Patient's age, educational status and their monthly income were statistically significantly associated with poor adherence. That is the odds of poor adherence to medications was 2.42 times higher in patients whose age less is than 50 years when compared with patients whose age is more than 50 years. And among the five levels of educational status, the odds of poor adherence was 2.82 times higher in patients with diploma degree when compared with patients having post graduate educational status. Also the odds of poor adherence to medications is 5.82 times more in patients with monthly income of $<5000$ Saudi Riyals when compared with patients having more than 30000SR as their monthly income (Table 1).

Characteristics of treatment care of our study subjects (time of diagnosis, self-perception about their health condition, regular health checkups at clinics, regular blood pressure checkup, and number of medications to take in a day) were highly statistically significantly associated with poor adherence to medications. The odds of poor adherence are significantly higher in patients who had been diagnosed with hypertension for $<1$ year (Odds Ratio: 2.06) and 2 to 5 years (1.98) when compared with patients who had been diagnosed with hypertension for more than 5 years. The odds are also higher (4.48) in patients who had expressed as "uncontrolled" about their health condition, patients who did not had regular checkup at clinics (7.30), patients who did not do regular blood pressure checkup at home (2.57) \& those who did not had device to check blood pressure at home (2.85), and in patients who were taking two and more than two medications $(1.62 ; 2.08)$ (Table 2).

The data does not provide the evidence of statistically significant association between the responses of patients towards the obstacles in taking medications and poor adherence to medications (Table 3).

In multivariable analysis, binary logistic regression by forward Wald method was used to predict poor adherence among hypertensive patients using the significant variables found in bivariate analysis. A model with the variables: age group ( $<50$ years), monthly income $(<=5000 \mathrm{SR})$, self-perception about their health (uncontrolled) and regular checkup at clinics (No) against a model with only constant was statistically significant indicating that the above variables as a set distinguishing between the patients with poor adherence and high adherence to medications $\left(\mathrm{X}^{2}=75.82 ; \mathrm{p}<0.001 ; \mathrm{DF}=7\right)$. Hosmer and Lemeshow test which tests for the goodness of fit for logistic regression models (an alternative to model chi-square test) had a value of $8.004(\mathrm{p}=0.433 ; \mathrm{df}=8)$. As the $\mathrm{p}$-value is greater than 0.05 , it can be inferred that the model's estimates fit the data at an acceptable level. This non-significance indicates that the model prediction does not significantly differ from the observed. Nagelkerke's $\mathrm{R}^{2}$ of 0.33 indicates a moderate relationship between prediction and grouping. The Wald criterion demonstrated that the variables in the model at the step4 (as given in the Table 4) made a significant contribution to the prediction of poor adherence to medications. The final model validation was carried out using classification table which summarizes the observed group and predicted group classification. The overall prediction success was $73.9 \%$ ( $71.5 \%$ for poor adherence and $76.6 \%$ for high adherence. The receiver operating characteristic (ROC) curve analysis for assessing predictive probabilities gave an area under the ROC curve value of 0.83 (95\% confidence interval: 0.75 to 0.87 ), indicating that the final model classifies the poor adherence group significantly better than by chance (Table 4).

\section{DISCUSSION}

The prevalence of poor medication adherence among Hypertension patients in this study was $55 \%$. It was also found that there is highly statistically significant independent association between the variables; age, monthly income, self-perception about patient's health condition, and regular clinical checkup with poor adherence to medications.

In the literature, it was found that during the first year of drug therapy, $77 \%$ of individuals with hypertension achieved 


\begin{tabular}{|c|c|c|c|}
\hline \multirow[t]{2}{*}{ Socio-demographic variables } & \multicolumn{2}{|c|}{ Adherence level - No. (\%) } & \multirow{2}{*}{$\begin{array}{l}\text { Odds ratio ( } 95 \% \\
\text { confidence interval) }\end{array}$} \\
\hline & Poor adherence $(<6)(n=155)$ & High adherence $(\geq 6)(n=127)$ & \\
\hline \multicolumn{4}{|l|}{ Age groups ( in years) } \\
\hline$\leq 50$ & $83(66.9)$ & $41(33.1)$ & $2.42(1.48,3.94)$ \\
\hline$>50$ & $72(45.6)$ & $86(54.4)$ & 1.0 \\
\hline \multicolumn{4}{|l|}{ Gender } \\
\hline Male & $62(56.4)$ & $48(43.6)$ & $1.08(0.67,1.75)$ \\
\hline Female & $93(54.4)$ & $78(45.6)$ & 1.0 \\
\hline \multicolumn{4}{|l|}{ Marital status } \\
\hline Married & $115(52.5)$ & $104(47.5)$ & 1.0 \\
\hline Others & $39(62.9)$ & $23(37.1)$ & $1.57(0.83,2.80)$ \\
\hline \multicolumn{4}{|l|}{ Residency } \\
\hline Riyadh & $124(53.4)$ & $108(46.6)$ & 1.0 \\
\hline Outside Riyadh & $27(61.4)$ & $17(38.6)$ & $1.38(0.71,2.67)$ \\
\hline \multicolumn{4}{|l|}{ Level of education } \\
\hline Illiterate & $21(47.7)$ & $23(52.3)$ & $0.91(0.32,2.3)$ \\
\hline Middle \& high school & $32(47.0)$ & $36(53.0)$ & $0.89(0.33,2.41)$ \\
\hline Diploma & $48(73.8)$ & $17(26.2)$ & $2.82(1.0,7.96)$ \\
\hline College graduate & $44(52.4)$ & $40(47.6)$ & $1.10(0.41,2.92)$ \\
\hline Post graduate & $10(50)$ & $10(50)$ & 1.0 \\
\hline \multicolumn{4}{|l|}{ Number of persons in a family } \\
\hline$<5$ & $63(55.5)$ & $50(44.5)$ & 1.0 \\
\hline $6-10$ & $80(54.4)$ & $67(45.6)$ & $0.95(0.58,1.55)$ \\
\hline$>10$ & $12(54.5)$ & $10(45.5)$ & $0.95(0.38,2.38)$ \\
\hline \multicolumn{4}{|l|}{ Monthly income (in Saudi Riyals) } \\
\hline$\leq 5000$ & $44(71)$ & $18(29)$ & $5.38(1.63,17.69)$ \\
\hline $5001-10000$ & $49(57)$ & $37(43)$ & $2.91(0.93,7.11)$ \\
\hline $10001-20000$ & $41(56.2)$ & $32(43.8)$ & $2.82(0.89,8.94)$ \\
\hline $20001-30000$ & $16(35.6)$ & $29(64.4)$ & $1.21(0.36,4.11)$ \\
\hline$>30000$ & $5(31.2)$ & $11(68.8)$ & 1.0 \\
\hline
\end{tabular}

\begin{tabular}{|c|c|c|c|}
\hline \multirow[t]{2}{*}{ Treatment characteristics } & \multicolumn{2}{|c|}{ Adherence level - No. (\%) } & \multirow{2}{*}{$\begin{array}{l}\text { Odds ratio }(95 \% \\
\text { confidence interval) }\end{array}$} \\
\hline & Poor adherence $(<6)(n=155)$ & High adherence $(\geq 6)(n=127)$ & \\
\hline \multicolumn{4}{|l|}{ Time of diagnosis (years) } \\
\hline$\leq 1$ & $31(64.6)$ & $17(35.4)$ & $2.06(1.05,4.1)$ \\
\hline $2-5$ & $56(63.6)$ & $32(36.4)$ & $1.98(1.15,3.41)$ \\
\hline$>5$ & $68(46.9)$ & $77(53.1)$ & 1.0 \\
\hline \multicolumn{4}{|c|}{ What would you say your condition? } \\
\hline Controlled & $105(47.7)$ & $115(52.3)$ & 1.0 \\
\hline Not controlled & $45(80.4)$ & $11(19.6)$ & $4.48(2.20,9.12)$ \\
\hline \multicolumn{4}{|l|}{ Regular clinical check } \\
\hline Yes & $72(39.8)$ & $108(60.2)$ & 1.0 \\
\hline No & $82(82.9)$ & $17(17.2)$ & $7.30(4.0,13.32)$ \\
\hline \multicolumn{4}{|c|}{ Regular blood pressure check at home } \\
\hline Yes & $49(40.8)$ & $71(59.2)$ & 1.0 \\
\hline No & 39 (63.9) & $22(36.1)$ & $2.57(1.36,4.86)$ \\
\hline No device at home & $67(66.3)$ & $34(33.7)$ & $2.85(1.65,4.95)$ \\
\hline \multicolumn{4}{|l|}{ No. of medications in a day } \\
\hline One & $72(48)$ & $78(52)$ & 1.0 \\
\hline Two & $54(60)$ & $36(40)$ & $1.62(0.96,2.76)$ \\
\hline More than two & $23(65.7)$ & $12(34.3)$ & $2.08(0.96,4.47)$ \\
\hline
\end{tabular}

adherence rates of $80 \%$ or better. ${ }^{11}$ Good adherence was found in $53.4 \%$ of 653 hypertensive patients in Malaysia. ${ }^{13}$ Another study in Tabuk city, Saudi Arabia, found the adherence levels among hypertension patients to be $53.0 \%{ }^{15}$ Some studies have reported non adherence of medications in these patients between $23 \%$ and $49.5 \% .^{12}$ This variation could be due either over or under estimation by patients and physicians while quantifying the adherence rates.

The socio-demographic characteristics of hypertensive patients in relation to their level of adherence to medications were not statistically significant except for age, 


\begin{tabular}{|c|c|c|c|}
\hline \multirow[t]{2}{*}{ Obstacles in taking medications } & \multicolumn{2}{|c|}{ Adherence level - No. (\%) } & \multirow{2}{*}{$\begin{array}{l}\text { Odds ratio }(95 \% \\
\text { confidence interval) }\end{array}$} \\
\hline & $\begin{array}{l}\text { Poor adherence }(<6) \\
\qquad(n=155)\end{array}$ & $\begin{array}{l}\text { High adherence }(\geq 6) \\
\qquad(n=127)\end{array}$ & \\
\hline \multicolumn{4}{|l|}{ Medications are not available } \\
\hline Yes & $24(54.5)$ & $20(45.5)$ & $0.98(0.51,1.87)$ \\
\hline No & $131(55)$ & $107(45)$ & 1.0 \\
\hline \multicolumn{4}{|c|}{ Taking medication factor (more than one medicines) } \\
\hline Yes & $61(53)$ & $54(47)$ & $0.88(0.54,1.41)$ \\
\hline No & $94(56.3)$ & $73(43.7)$ & 1.0 \\
\hline \multicolumn{4}{|c|}{$\begin{array}{l}\text { Psychological factors (lack of confidence in } \\
\text { medication for controlling the disease) }\end{array}$} \\
\hline Yes & $41(46.6)$ & $47(53.4)$ & $0.61(0.37,1.02)$ \\
\hline No & $114(58.8)$ & $80(41.2)$ & 1.0 \\
\hline \multicolumn{4}{|c|}{$\begin{array}{l}\text { Financial factors (if medications have to be } \\
\text { purchased by the patient himself) }\end{array}$} \\
\hline Yes & $31(67.4)$ & $15(32.6)$ & $1.87(0.96,3.64)$ \\
\hline No & $124(52.5)$ & $112(47.5)$ & 1.0 \\
\hline \multicolumn{4}{|c|}{$\begin{array}{l}\text { Health care providers and medical system factors } \\
\text { (difficulties in seeing appropriate clinician) }\end{array}$} \\
\hline Yes & $42(61.8)$ & $26(38.2)$ & $1.44(0.83,2.52)$ \\
\hline No & $113(52.8)$ & $101(47.2)$ & 1.0 \\
\hline
\end{tabular}

Table 4: Associated factors of poor adherence to medications in hypertensive patients (by multivariable analysis)

\begin{tabular}{|c|c|c|c|c|c|}
\hline Associated factors & B & $\begin{array}{l}\text { Standard } \\
\text { error }\end{array}$ & $\begin{array}{c}\text { Wald } \\
\text { statistics }\end{array}$ & $\begin{array}{l}\text { Adjusted odds } \\
\text { ratio (95\% C.I.) }\end{array}$ & p-value \\
\hline \multicolumn{6}{|l|}{ Age group (years) } \\
\hline$\leq 50$ & 0.83 & 0.29 & 8.018 & $2.30(1.29,4.10)$ & 0.005 \\
\hline$>50$ & -- & -- & -- & 1.0 (Ref.) & -- \\
\hline \multicolumn{6}{|l|}{ Monthly income } \\
\hline$\leq 5000$ & 1.88 & 0.70 & 7.23 & $6.58(1.67,25.97)$ & 0.007 \\
\hline $5001-10000$ & 1.26 & 0.66 & 3.66 & $3.54(0.97,12.95)$ & 0.056 \\
\hline $20001-30000$ & 0.54 & 0.72 & 0.56 & $1.71(0.42,7.0)$ & 0.455 \\
\hline$>30000$ & -- & -- & -- & 1.0 (Ref.) & -- \\
\hline \multicolumn{6}{|c|}{ What would you say your condition? } \\
\hline Controlled & -- & -- & -- & 1.0 (Ref.) & -- \\
\hline Not controlled & 0.98 & 0.41 & 5.80 & $2.66(1.20,5.90)$ & 0.016 \\
\hline \multicolumn{6}{|l|}{ Regular checkup at clinics } \\
\hline Yes & -- & -- & -- & 1.0 (Ref.) & -- \\
\hline \multicolumn{6}{|l|}{ Nagelkerke Pseudo $\mathrm{R}^{2}=0.33$} \\
\hline \multicolumn{6}{|l|}{ Goodness of fit Hosmer \& } \\
\hline Lemeshow=8.004 $(p=0.433)$ & & & & & \\
\hline
\end{tabular}

and monthly income. Our results indicates that, younger age ( $<50$ years), and with low monthly income were more likely to have poor adherence to their medications. Other studies also shown that, non-adherence was higher in patients of younger age group suffering with hypertension and psychiatric disorders. ${ }^{16,17}$ The effect of income on poor adherence also observed in a study conducted in Sudan. ${ }^{18}$ Also, people in Saudi Arabia are not well aware about the importance of adherence to their medications and the possible complications for not adhering due their lack of knowledge. Lack of health education, and unawareness of the complications due chronic illness have been observed in study from Tabuk. ${ }^{15}$

In addition, patients who do not have regular clinical checkups, who do not perform regular home checkups and those who had expressed as uncontrolled towards their health condition, were having poor adherence to their medications. These findings goes in line with other studies findings, 'irregularity of follow-up' and 'inability to see their family physicians' as some of the reasons for poor adherence. ${ }^{16,19}$ Lack of family support such as, 'not having 
been told to continue treatment' and 'patient's disbelief about the value and need for adherence' were the reasons for poor adherence among patients suffering with other chronic diseases. ${ }^{20}$

Our study found that the number of medications do not affect the compliance of patients to their medications while another study shows that fixed dose medication have higher levels of patients adherence to medication. The reason behind this might be the large sample size of the trial $(\mathrm{n}=32331)^{21}$ in contrast, another study report that complexity of the treatment regimen was one of the reason for poor adherence to medications. ${ }^{17}$ Also, our study found that patients who have higher adherence to their medication had controlled blood pressure, which is consistent with another study that shows high-adherence patients were more likely to achieve blood pressure control. ${ }^{22}$

\section{CONCLUSION}

This study has brought out some of the associated factors of poor adherence to medications, among the complex web of factors prevalent in patients suffering with chronic diseases. It is not solely the patient problem but is impacted by both care providers and the healthcare system. To improve adherence, patient's personal issues must be fully understood at a family level and treatment care issues at healthcare facilities. During periodical checkup, the clinicians should effectively communicate the importance of following treatment plans and to offer medication support services to patients and their caregivers. Specific strategies may include supporting public education campaigns regarding compliance with chronic disease management, in particular hypertension. Also, the use of electronic and telephonic reminders, packaging features (e.g. dose tracking), and other tools may help patients to improve adherence.

\section{Limitations}

This study, cannot determine causation, as it is a crosssectional study and patients responses were subjective. Also, the influence of the researchers during the data collection from patients can lead to bias, but could not have much effect on the study outcome.

\section{ACKNOWLEDGMENTS}

The authors would like to acknowledge all patients who had participated in this study.

\section{DECLARATION}

The authors did not receive any financial support to carry out this study. Also no conflict of interest.

\section{REFERENCES}

1. Rodgers $\mathrm{A}$, Lawes $\mathrm{C}$ and Mac Mohan S. Reducing the global burden of blood pressure-related cardiovascular disease. J Hypertens Suupl 2000; 18(1):S3-S6.

2. Al-Nozha MM, Abdullah M, Arafah MR, Khalil MZ, Khan NB, Al-Mazrou YY, et al. Hypertension in Saudi Arabia. Saudi Med J 2007; 28(1):77-84.

3. Al-Hamdan N, Saeed A, Kutbi A, Choudhry AJ and Nooh R. Characteristics, Risk Factors, and Treatment Practices of Known Adult Hypertensive Patients in Saudi Arabia. Int J Hypertens 2010; 168739.

4. Aram VC, George LB, Henry RB, William CC, Lee AG, Joseph $\mathrm{LI}$, et al. Joint National Committee on Prevention, Detection, Evaluation, and Treatment of High Blood Pressure; National Heart, Lung, and Blood Institute; National High Blood Pressure Education Program Coordinating Committee: Seventh report of the Joint National Committee on Prevention, Detection, Evaluation, and Treatment of High Blood Pressure. Hypertension 2003; 42(6):1206-1252.

5. Al-Hamdan NA, Kutbi A, Choudhry AJ, Nooh R, Shoukri M and Mujib SA. WHO Stepwise approach to NCD Surveillance Country-Specific Standard Report Saudi Arabia. 2005.

6. World Health Organization. Adherence to Long-Term Therapies: Evidence for Action [Internet]. Geneva: World Health Organization; 2003.

7. Hüther J, Von Wolff A, Stange DH, Arter M, Baehr M, Dartsch D, et al. Incomplete medication adherence of chronically ill patients in German primary care. Patient preference and adherence 2013; 7; 237.

8. Rickles NM, Maclean GL, Hess K, Farmer KC, Yurkon AM, $\mathrm{Ha}$ CC, et al. Teaching Medication Adherence in US Colleges and Schools of Pharmacy. American Journal of Pharmaceutical Education 2012; 76 (5):79.

9. Chobanian AV, Bakris GL, Black HR, Cushman WC, Green LA, Izzo JL, et al. Seventh report of the Joint National Committee on Prevention, Detection, Evaluation, and Treatment of High Blood Pressure.Hypertension 2003;42(6):1206-1252.

10. Saeed AA, Al-Hamdan NA, Bahnassy AA, Abdalla AM, Abbas MA and Abuzaid LZ. Prevalence, Awareness, Treatment, and Control of Hypertension among Saudi Adult Population: A National Survey. Int J Hypertens 2011:174135.

11. Hashmi SK, Afridi MB, Abbas K,Sajwani RA, Saleheen D,Frossard PM, et al. Factors associated with adherence to anti-hypertensive treatment in Pakistan. PLoS ONE, 2007,2:e280.

12. Al-Qasem A, Smith F and Clifford S. Adherence to medication among chronic patients in Middle Eastern countries: review of studies. Eastern Mediterranean Health Journal 2011; 17:4:356-363.

13. Ramli A, Ahmad NS and Paraidathathu T. Medication adherence among hypertensive patients of primary health clinics in Malaysia. Patient Preference and Adherence 2012:6: 613-622.

14. Morisky DE, Green LW and Levine DM. Concurrent and predictive validity of a self-reported measure of medication adherence. Med Care 1986; 24(1):67-74.

15. Khali SA and Elzubier AG. Drug compliance among hypertensive patients in Tabuk, Saudi Arabia. Journal of hypertension 1997; 15(5):561-565.

16. Al-Sowielem LS and Elzubier AG. Compliance and knowledge of hypertensive patients attending PHC centers in Al-Khobar, Saudi Arabia. Eastern Mediterranean Health Journal 1998; 4(2):301-307.

17. Fido $A A$ and Husseini AM. Noncompliance with treatment among 
psychiatric patients in Kuwait. Medical Principles and Practice 1998; 7: 28-32.

18. Elzubier AG, Husain AA, Suleiman IA and Hamid ZA. Drug compliance among hypertensive patients in Kassala, eastern Sudan. Eastern Mediterranean Health Journal 2000; 6: 100-105.

19. Al-Saffar $\mathrm{N}$ and Deshmukh AA. Effect of information leaflets and counselling on antidepressant adherence: open randomized controlled trial in a psychiatric hospital in Kuwait. International Journal of Pharmacy Practice 2005; 13:123-132.
20. Abdul Jabbar M and Al-Shammaari SA. Compliance in Saudi epileptic patients: Determinants of compliance in Saudi epileptic patients. Annals of Saudi Medicine 1993; 13:60-63.

21. Gupta AK, Arshad S and Poulter NK. Compliance, Safety, and Effectiveness of Fixed-Dose Combinations of Antihypertensive Agents: A Meta-Analysis. Hypertension 2010; 55:399-407.

22. Al-Mehza AM, Al-Muhailije, Khalfan MM and Al-Yahya AA. Drug Compliance among Hypertensive Patients; an Area Based Study. Eur J Gen Med 2009; 6(1): 6-10.

Authors Contribution:

SAS- Concept, design of study, data analysis and developing of final manuscript; AAS - Design of study, Literature review, data analysis and first draft of manuscript; AAH - Design of study, Literature review, data collection and data analysis; AA - Design of study, Literature review, data collection, data analysis and first draft of manuscript; DA - Design of study, Literature review, data collection and data analysis; HAG - Design of study, Literature review, data collection and data analysis; RA - Design of study, Literature review, data collection and data analysis; AH - Critical review of manuscript and intellectual content. 